02.2;05;06;13.1;13.3

\title{
Формирование наноразмерных пленок золота в условиях многократного автооблучения при ионно-лучевом осаждении
}

\author{
() С.А. Шарко ${ }^{1}$, А.И. Серокурова ${ }^{1}$, Н.Н. Новицкий ${ }^{1}$, А.И. Стогний ${ }^{1}$, В.А. Кецко ${ }^{2}$ \\ ${ }^{1}$ НПЦ НАН Беларуси по материаловедению, Минск, Беларусь \\ ${ }^{2}$ Институт общей и неорганической химии им. Н.С. Курнакова РАН, Москва, Россия \\ E-mail: sharko@physics.by
}

Поступило в Редакцию 21 июня 2021 г.

В окончательной редакции 22 сентября 2021 г.

Принято к публикации 23 сентября 2021 г.

\begin{abstract}
Методом ионно-лучевого осаждения-распыления впервые получены однородные пленки золота толщиной несколько десятков нанометров на кремниевых и кварцевых подложках. Показано, что в условиях воздействия высокоэнергетической составляющей потока распыленных атомов происходит преимущественный латеральный рост наноразмерных слоев металла вдоль поверхности подложки. Решающую роль в формировании нанометровой пленки золота играют процессы упругого столкновения распыленных атомов металла с атомами подложки и растущей пленки. Применение операции многократного осаждения-распыления позволяет подавить процесс гранулирования и получить пленки золота с лучшими характеристиками, чем при однократном осаждении.

Ключевые слова: ионно-лучевое осаждение-распыление, наноразмерная пленка золота, электрическое сопротивление, шероховатость поверхности, автооблучение.
\end{abstract}

DOI: 10.21883/PJTF.2022.01.51875.18930

Получение материалов в наноразмерном состоянии со свойствами, характерными для массивных образцов, является фундаментальной научно-технической проблемой. Ее решение позволяет глубже понять, с одной стороны, поведение вещества в предельном состоянии, когда сильное влияние оказывают квантовые эффекты, a с другой - например, взаимодействие магнитных и оптических явлений, а также решить ряд связанных с ними задач практического характера. Возможность эффективного управления светом путем воздействия на оптические свойства среды внешними магнитными полями ограничивается малостью величин магнитооптических эффектов [1]. Одним из путей их повышения является использование материалов, в которых требуемые оптические характеристики достигаются благодаря подбору геометрических параметров структуры, а не химического состава. В частности, создание периодических структур в виде металлических решеток на диэлектрической подложке [1] позволяет локализовать энергию электромагнитного поля на интерфейсе металл/диэлектрик за счет возбуждения поверхностных электромагнитных волн (поверхностных плазмон-поляритонов) и, как следствие, усилить взаимодействие света с веществом. При этом наиболее интенсивное возбуждение плазмонполяритонов наблюдается при использовании наноразмерных пленок благородных металлов, в частности золота [1-3]. Однако для формирования структур магнитоплазмоники $[1,3-5]$ нужны ультратонкие пленки с большой степенью однородности.

Существует большое количество работ [6-8], в которых синтезировались пленки золота толщиной десяткисотни нанометров различными методами [6], такими как ионно-лучевое осаждение, термическое испарение, химическое осаждение из паровой фазы, импульсное лазерное осаждение, молекулярно-лучевая эпитаксия, катодное, ионно-плазменное и магнетронное распыление. Во всех этих работах не решена проблема получения сплошных и однородных пленок золота из-за неудовлетворительной адгезии слоя металла к подложке, а также гранулирования в самой пленке. Последнее связано с химической инертностью золота к материалам иной природы, что обусловливает преимущественное взаимодействие атомов золота друг с другом, а не с атомами подложки [6].

Целью настоящей работы является синтез сплошных однородных пленок золота толщиной несколько десятков нанометров на кремниевых и кварцевых подложках методом вакуумного осаждения при ионно-лучевом распылении [2,9].

Перед осаждением слоя золота проводилась очистка кремниевых и кварцевых подложек от посторонних поверхностных примесей в течение $120 \mathrm{~s}$ пучком ионов кислорода с энергией менее $0.3 \mathrm{keV}$ и плотностью тока ионного пучка $0.1-0.15 \mathrm{~mA} / \mathrm{cm}^{2}$. Осаждение осуществлялось с помощью установки двойного ионнолучевого осаждения-распыления с широкоапертурным источником ионов [10]. Нанесение слоя золота на предварительно подготовленную подложку производилось распылением мишени золота ионами аргона с энергией $1-1.3 \mathrm{keV}$ и плотностью тока ионного пучка $0.1-0.25 \mathrm{~mA} / \mathrm{cm}^{2}$. Рабочее давление во время осаждения пленки не превышало $10^{-2} \mathrm{~Pa}$, остаточное давление в рабочей камере составляло $10^{-3} \mathrm{~Pa}$. Для откачки до требуемого уровня вакуума использовался масляный 


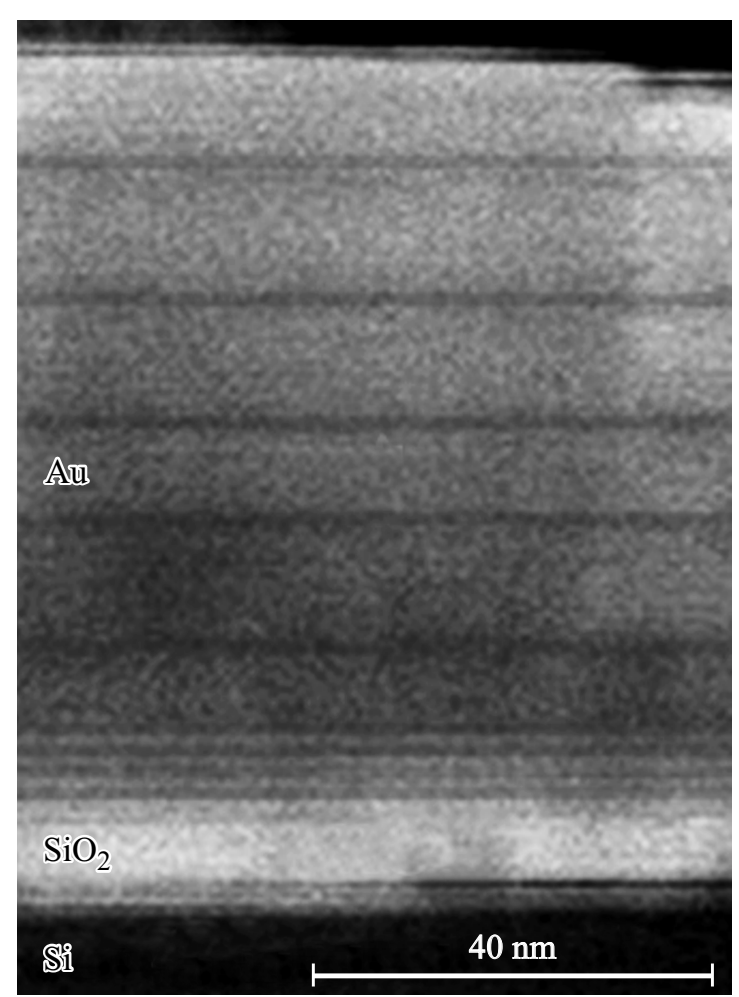

Рис. 1. РЭМ-изображение поперечного сечения пленки золота толщиной $90 \mathrm{~nm}$ на кремнии при многократном осаждении.

диффузионный насос. Время осаждения золота составляло $5 \mathrm{~min}$. При многократном применении операции осаждения-распыления нанесение слоя металла проводилось в тех же условиях в течение $60 \mathrm{~s}$, а затем осуществлялось распыление ионами аргона тех же энергий в течение $30 \mathrm{~s}$. С целью обеспечения улучшенной адгезии первые слои металла распылялись полностью до исчезновения металлической проводимости. Цикл осаждения-распыления повторялся 10 раз.

Анализ поверхности и поперечных сечений пленок золота проводился на растровом электронно-ионном микроскопе РЭИМ Helios NanoLab 600 (производитель FEI Company, США). Морфология поверхности исследовалась методом атомно-силовой микроскопии на зондовом сканирующем микроскопе NanoEducator (производитель NT-MDT, РФ). Оптические спектры отражения и пропускания пленок золота на кварцевых подложках были получены на спектрофотометре Cary-500 (производитель Agilent Technologies, США) в интервале длин волн от 400 до $800 \mathrm{~nm}$.

На рис. 1 хорошо видна слоистая структура, образуемая в результате воздействия атомов золота на подложку, а затем на металлическую пленку по меpe еe роста на подложке. На поперечном сечении в области интерфейса пленка/подложка не наблюдается никаких отслоений, а сам интерфейс представляет собой сплошную и ровную поверхность раздела, что свидетельствует об отсутствии химического взаимодействия между пленкой и подложкой. После каждой операции распыления происходит преимущественно латеральный рост слоя металла вдоль поверхности, когда адсорбированные атомы присоединяются к растущему слою до его полного зарастания. Это является доказательством усиления связи атом металла-атом подложки и, как следствие, улучшения адгезии слоя золота к подложке.

Для объяснения формирования качественного сплошного слоя золота на поверхности подложки необходимо учесть, что распределение распыленных атомов металла по энергиям имеет непрерывный спектр до максимальной энергии $E_{\max }[11]$, определяемой энергией распыляющих ионов. В потоке атомов распыляемого вещества можно условно выделить две компоненты: основную и высокоэнергетическую [2]. Основная состоит из атомов со средней энергией, примерно равной энергии сублимации $U$ (для золота $\sim 3.8 \mathrm{eV} /$ atom [12]), а высокоэнергетическая включает атомы с энергией, на порядок превышающей $U$ [11].

Согласно оценкам, проведенным с использованием программного пакета SRIM (www.srim.org, [13]), большинство распыленных атомов золота с энергией до $10 \mathrm{eV}$ проникает в подложку кремния или кварца на глубину не более $0.8 \mathrm{~nm}$. Они конденсируются на поверхности подложки и формируют слой металла.

Высокоэнергетические атомы золота (до $300 \mathrm{eV}$ ) на начальной стадии осаждения способны внедряться в приповерхностный слой подложки на глубину до семи постоянных решетки (до $2.8 \mathrm{~nm}$ [14]) с формированием в этой области точечных дефектов. Однако быстрое убывание количества распыленных атомов с ростом энергии в силу асимметричности функции распределения позволяет ограничиться максимальными энергиями до $20 \mathrm{eV}$ (атомы с такими энергиями проникают в подложку на $1 \mathrm{~nm})$. Действительно, частиц с энергией свыше $20 \mathrm{eV}$ значительно меньше $0.01 \%$, а с энергиями свыше $100 \mathrm{eV}$ - менее $10^{-6 \%}$. Поэтому подавляющее большинство точечных дефектов будет формироваться в приповерхностном слое подложки на глубине не более двух постоянных решетки, т. е. $1 \mathrm{~nm}$.

Особенности процессов распыления, а следовательно, и формирования тонких пленок осаждаемого вещества определяются кинетикой столкновительных процессов $[15,16]$, идущих как на поверхности подложки с участием атомов металла и подложки, так и на поверхности растущей металлической пленки с участием только атомов металла. Все процессы столкновения атомов заключены между двумя предельными случаями передачи кинетической энергии: абсолютно упругого и абсолютно неупругого удара. В последнем случае изменяется внутреннее состояние атомов, которое можно не принимать во внимание.

При центральном ударе максимальная доля $\gamma$ передаваемой энергии определяется соотношением масс налетающего $M_{1}$ и покоящегося $M_{2}$ атомов: $\gamma=4 M_{1} M_{2} /\left(M_{1}+M_{2}\right)^{2}[16]$. Взаимодействие атомов золота с более легкими атомами кремния и кислорода 


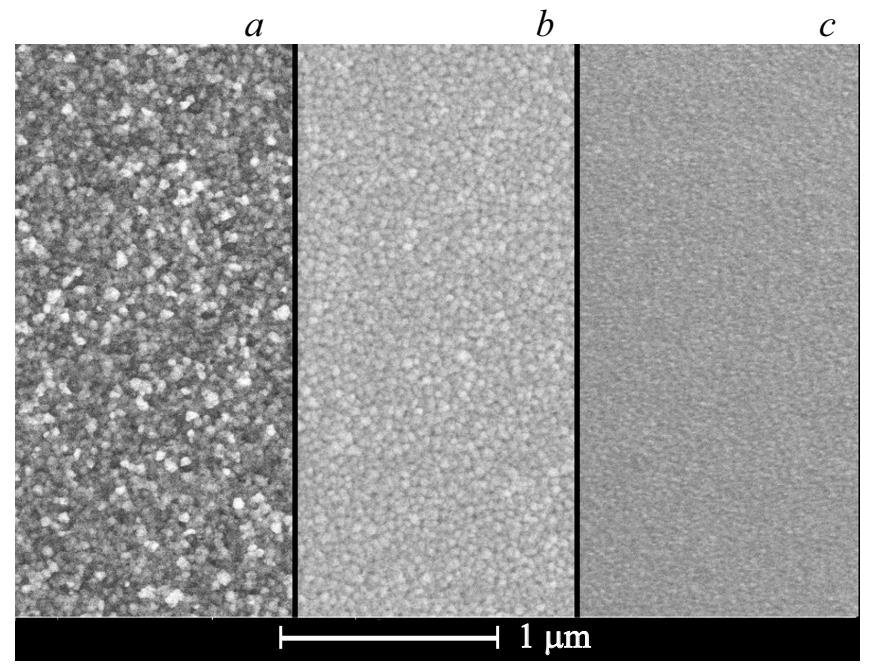

Рис. 2. РЭМ-изображение поверхности пленок золота при однократном $(a)$, двукратном $(b)$ и многократном $(c)$ осаждении на исходную поверхность кремния.

сопровождается передачей им части энергии, равной соответственно $\gamma=0.44$ и 0.22. Двигаясь в первоначальном направлении, они останавливаются на некоторой глубине в приповерхностных областях подложки с образованием точечных дефектов. При взаимодействии атомов золота друг с другом в процессе автооблучения растущей пленки происходит полная передача кинетической энергии $(\gamma=1)$. В случае центрального

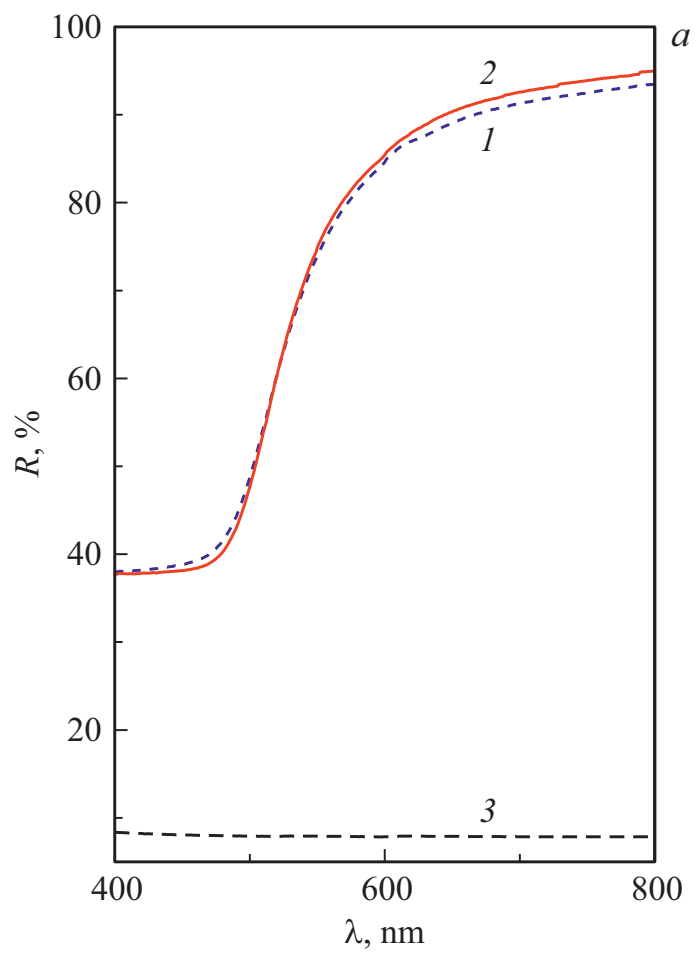

удара это приводит к обмену энергией между атомами металла. Толщина слоя металла, особенно при повторной и последующих операциях осаждения, значительно больше глубины внедрения атомов золота, которая по данным SRIM не превосходит $0.6 \mathrm{~nm}$ для самых высокоэнергетических атомов $(300 \mathrm{eV})$ потока распыленного вещества и $0.3 \mathrm{~nm}$ для атомов с энергией $20 \mathrm{eV}$. В этом случае увеличение количества точечных дефектов в приповерхностных областях подложки под слоем металла можно объяснить механизмом прямого либо каскадного выбивания атомов золота из слоя в подложку в процессе абсолютно упругого столкновения с такими же атомами высоких энергий.

Повторное осаждение слоя металла в указанных выше условиях позволяет не менее чем в 2 раза увеличить число внедренных атомов металла в приповерхностных областях подложки. Точечные дефекты в дополнение к уже имеющимся (внедренным при предыдущем осаждении) приводят к улучшению адгезии [2] из-за образования дополнительных физических связей между внедренным и осажденным атомами золота. Это обеспечивает формирование на подложке сплошного слоя золота толщиной в несколько моноатомных слоев и последующее нанесение на его поверхность наноразмерной пленки того же металла.

Все указанное выше приводит к улучшению поверхностной морфологии при переходе к многократному воздействию пучком распыленных атомов высокоэнергетической составляющей потока на растущую пленку. Сравнение результатов исследований с помощью

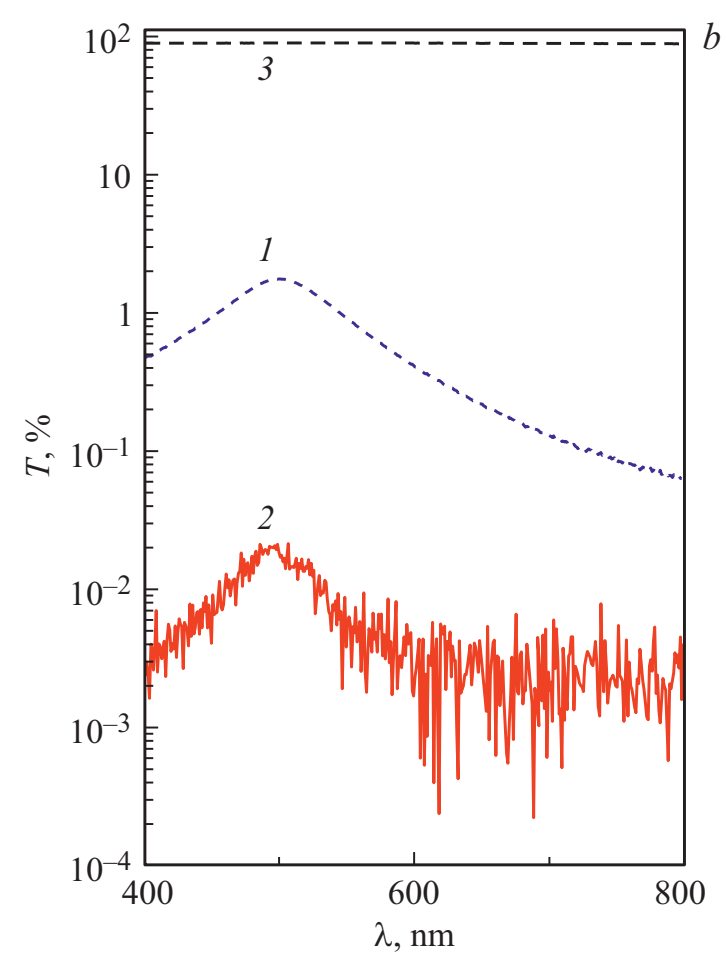

Рис. 3. Спектры отражения $(a)$ и пропускания $(b)$ пленок золота на кварце, полученных при однократном осаждении $(1)$ и с применением многократного осаждения-распыления (2). 3 - соответствующие спектры кварца. 
атомно-силовой микроскопии наноразмерных пленок золота, полученных на кремниевых подложках, показало, что среднеквадратическая шероховатость $R_{q}$ поверхности тонких пленок золота при однократном осаждении составляет $1.2 \mathrm{~nm}$, при повторном - $0.8 \mathrm{~nm}$, а при многократном - $0.3 \mathrm{~nm}$. При этом средний размер зерен, согласно данным исследований, выполненных посредством растровой электронной микроскопии (РЭМ), уменьшается при переходе к многократному осаждению (рис. 2). В последнем случае происходит практически полное подавление гранулирования пленок золота за счет увеличения плотности зародышей в результате автооблучения высокоэнергетическими атомами золота, что приводит к повышению степени их однородности и сплошности. Это способствует улучшению адгезии пленки к подложке [17].

Оптические свойства пленок золота на кварцевых подложках в области длин волн от 400 до $800 \mathrm{~nm}$ после применения операции многократного осаждения не ухудшаются (рис. 3). Резкое возрастание коэффициента отражения в области длин волн $520-550 \mathrm{~nm}$, а также наличие пика на кривой пропускания свидетельствуют о подавлении локализованного плазмонного резонанса [3], обычно наблюдаемого в этой области спектра.

Таким образом, продемонстрирован новый подход к формированию сплошных однородных наноразмерных пленок золота с преимущественно латеральным ростом за счет автостимулирования формирующегося слоя собственным потоком адатомов. Использование методики многократного осаждения-распыления дает возможность высокоэнергетической части потока осаждаемых атомов многократно воздействовать на формируемую пленку. За счет этого подавляется процесс гранулирования и обеспечиваются высокая адгезия слоя металла к подложке и получение нанометровых пленок золота высокого качества. Показано, что простая модель абсолютно упругих парных столкновений позволяет на качественном уровне описать процесс формирования однородных пленок золота на начальной стадии.

\section{Финансирование работы}

Работа выполнена при финансовой поддержке резервного фонда Президента Республики Беларусь на 2021 г., а также в рамках Белорусского республиканского фонда фундаментальных исследований (совместный белорусско-российский проект Ф20Р-115) и Российского фонда фундаментальных исследований (гранты № 19-0800643 и 18-29-11026).

\section{Конфликт интересов}

Авторы заявляют, что у них нет конфликта интересов.

\section{Список литературы}

[1] П.Н. Найденов, А.Л. Чехов, О.Л. Голикова, А.В. Беспалов, А.А. Гераськин, С.С. Савин, Т.В. Мурзина, ФТТ, 61 (9), 1706 (2019). DOI: 10.21883/FTT.2019.09.48114.22N [P.N. Naydenov, A.L. Chekhov, O.L. Golikova, A.V. Bespalov, A.A. Geraskin, S.S. Savin, T.V. Murzina, Phys. Solid State, 61 (9), 1658 (2019). DOI: 10.1134/S106378341909018X].

[2] А.И. Стогний, Н.Н. Новицкий, О.М. Стукалов, А.И. Демченко, В.И. Хитько, Письма в ЖТФ, 30 (6), 87 (2004). [A.I. Stognij, N.N. Novitsky, O.M. Stukalov, A.I. Demchenko, V.I. Khitko, Tech. Phys. Lett., 30 (3), 256 (2004). DOI: $10.1134 / 1.1707185]$.

[3] V. Amendola, R. Pilot, M. Frasconi, O.M. Maragó, M.A. Iatí, J. Phys.: Condens. Matter., 29 (20), 203002 (2017). DOI: $10.1088 / 1361-648 X / a a 60 f 3$

[4] I. Razdolski, A.L. Chekhov, A.I. Stognij, A. Stupakiewicz, Phys. Rev. B, 100 (4), 045412 (2019).

DOI: $10.1103 /$ PhysRevB.100.045412

[5] A.L. Chekhov, V.L. Krutyanskiy, V.A. Ketsko, A.I. Stognij, T.V. Murzina, Opt. Mater. Express, 5 (7), 1647 (2015). DOI: 10.1364/OME.5.001647

[6] R. Malureanu, A. Lavrinenko, Nanotechnol. Rev., 4 (3) 259 (2015). DOI: $10.1515 /$ ntrev-2015-0021

[7] Y. Kombluth, R. Mathews, L. Parameswaran, L.M. Racz, L.F. Velasquez-Garcia, Additive Manufacturing, 36, 101679 (2020). DOI: 10.1016/j.addma.2020.101679

[8] L. Leandro, R. Malureanu, N. Rozlosnik, A. Lavrinenko, ACS Appl. Mater. Interfaces, 7 (10) 5797 (2015). DOI: $10.1021 / \mathrm{am} 508681 \mathrm{u}$

[9] C. Bundesmann, H. Neumann, J. Appl. Phys., 124 (23), 231102 (2018). DOI: $10.1063 / 1.5054046$

[10] А.И. Стогний, Н.Н. Новицкий, О.М. Стукалов, Письма в ЖТФ, 28 (1), 39 (2002). [A.I. Stognij, N.N. Novitskii, O.M. Stukalov, Tech. Phys. Lett., 28 (1), 17 (2002). DOI: $10.1134 / 1.1448630]$.

[11] M.V. Thompson, Nucl. Instrum. Meth. Phys. Res. B, 18 (1-6), 411 (1986). DOI: 10.1016/S0168-583X(86)80067-2

[12] Д. Фальконе, УФН, 162 (19), 71 (1992). DOI: $10.3367 /$ UFNr.0162.199201c.0071 [G. Falcone, La Rivista del Nuovo Cimento, 13 (1), 1 (1990).

[13] J.P. Biersack, W. Eckstein, Appl. Phys. A, 34 (2), 73 (1984). DOI: $10.1007 / \mathrm{BF} 00614759$

[14] Дж. Эмсли, Элементы, пер. с англ. (Мир, М., 1993), c. 66-67, 91-92. [J. Emsley, The Elements, 2nd ed. (Oxford University Press, 1998).].

[15] Л.Д. Ландау, Е.М. Лифшиц, Теоретическая физика (Физматлит, М., 2004), т. I, с. 63-65.

[16] Y. Yamamura, H. Tawara, Atom. Data Nucl. Data Tabl., 62 (2), 149 (1996). DOI: 10.1006/adnd.1996.0005

[17] W. Ensinger, Nucl. Instrum. Meth. Phys. Res. B., 127-128, 796 (1997). DOI: 10.1016/S0168-583X(97)00010-4 